\title{
Discovery of Carbono(di)thioates as Indoleamine 2,3-Dioxygenase 1 Inhibitors
}

Miyuki Kumazawa, ${ }^{\dagger}$ Manabu Tejima ${ }^{\dagger}$ Miwa Fukuda, ${ }^{\ddagger}$ Shota Takeda,${ }^{\dagger}$ Kenji Suzuki,${ }^{\dagger}$ Yukiko Mizumoto ${ }^{\dagger}$ Kakeru Sato, ${ }^{\dagger}$ Minoru Waki, ${ }^{\ddagger}$ Hiroyuki Miyachi,,$\|$ Akira Asai,§ Osamu Takikawa,\# Tomoko Hashimoto, ${ }^{\dagger}$ Osamu Ohno ${ }^{\dagger}$ and Kenji Matsuno. ${ }^{\dagger}, *$ ${ }^{\dagger}$ Laboratory of Medicinal Chemistry, Department of Chemistry and Life Science, School of Advanced Engineering, Kogakuin University, 2665-1 Nakano-machi, Hachi-oji, Tokyo 1920015, Japan, $¥$ Graduate School of Medicine, Dentistry and Pharmaceutical Sciences, Okayama University, 1-1-1 Tsushima-naka, Kita-ku, Okayama 700-8530, Japan, sGraduate School of Pharmaceutical Sciences, University of Shizuoka, 52-1 Yada, Suruga-ku, Shizuoka 422-8526, Japan, \#National Institute for Longevity Sciences, National Center for Geriatrics and Gerontology, 36-3 Gengo, Morioka, Obu, Aichi 474-8522, Japan.

\section{Supporting information}

\section{Synthesis and characterization of compounds}

${ }^{1} \mathrm{H}$ NMR spectra were recorded with Varian VNMRS-400 (400 MHz), JEOL JNMECZ400S (400 MHz) or JEOL HNM-ECX400 (400 MHz) NMR spectrometers in the indicated solvent. Chemical shifts $(\delta)$ are expressed in parts per million (ppm) relative to the internal standard tetramethylsilane. The peak patterns are indicated as follows: $\mathrm{s}$, singlet; d, doublet; dd, doublet of doublets; ddd, doublet of doublet of doublets; $t$, triplet; $\mathrm{dt}$, doublet of triplets; m, multiplet; brs, broad singlet; brd, broad doublet. The coupling constants (J) are reported in Hertz $(\mathrm{Hz})$. High resolution FAB-MS spectra were recorded on a VG70-SE. EI-MS spectra were recorded on a JEOL JMS-GCmate II . HPLC spectra were recorded as follows: (method A) on Shimadzu LC-10AT separations module with LC-10AV photodiode array detector. The sample was applied on a Waters XBrige Amide column $(2.1 \mathrm{~mm} \times 100 \mathrm{~mm}, 3.5 \mu \mathrm{m})$ with a Waters XBrige Amide guard cartridge $(2.1 \times 10$ $\mathrm{mm}, 3.5 \mu \mathrm{m})$ and eluted at $1 \mathrm{~mL} / \mathrm{min}$ with $0.5 \mathrm{~min}(0 \% \mathrm{~B})$, then 5 min gradient $(0 \% \mathrm{~B}$ to $100 \% \mathrm{~B}$ ) and then maintaining the final condition for $2 \mathrm{~min}$, where solvent $\mathrm{A}$ was water $\left(0.1 \% \mathrm{H}_{3} \mathrm{PO}_{4}\right.$ buffer) and solvent B was acetonitrile. (method B) on Shimadzu LC-20AD separations module with SPD-20A photodiode array detector. The sample was applied on a Waters XBrige $\mathrm{C}_{18}$ column $(2.1 \mathrm{~mm}$ x $50 \mathrm{~mm}, 5 \mu \mathrm{m})$ with a Waters XBrige $\mathrm{C}_{18}$ guard cartridge $(2.1 \times 10 \mathrm{~mm}, 5 \mu \mathrm{m})$ and eluted at $1 \mathrm{~mL} / \mathrm{min}$ with $0.5 \mathrm{~min}(0 \% \mathrm{~B})$, then $5 \mathrm{~min}$ gradient ( $0 \% \mathrm{~B}$ to $100 \% \mathrm{~B}$ ) and then maintaining the final condition for $2 \mathrm{~min}$, where solvent $\mathrm{A}$ was water $\left(0.1 \% \mathrm{H}_{3} \mathrm{PO}_{4}\right.$ buffer $)$ and solvent $\mathrm{B}$ was acetonitrile. Column 
chromatography was performed on columns packed with silica gel from Fuji Silysia chemicals (CHROMATOREX PSQ 60B or CHROMATOREX PQN 100B) or Kanto chemicals (Silicagel 60 for flash chromatography). Alternatively, Yamazen smart flash EPCLC AI-580S was used for purification. Silica gel TLC plates from Merck (Kiesel gel 60 F254: $0.25 \mathrm{~mm}$ silica gel precoated glass plates with fluorescent indicator visualizable at $254 \mathrm{~nm}$ ) were used for thin layer chromatography (TLC). Reagents were used without further purification.

\section{(RS)-4-Methoxycarbonyloxazolidine-2-thione}<smiles>CCN(CC)CCSC1NC(C(=O)OC)CO1</smiles>

1,1'-Thiocarbonyldiimidazole (356 mg, $2.00 \mathrm{mmol})$ and triethylamine $(277 \mu \mathrm{L}, 1.99$ $\mathrm{mmol}$ ) were added to a solution of DL-serine methyl ester hydrochloride (310 mg, 1.99 mmol) in $\mathrm{CH}_{2} \mathrm{Cl}_{2}(8 \mathrm{~mL})$. The mixture was stirred overnight under Ar atmosphere at room temperature. After evaporation, the resulting residue was purified by column chromatography on silica gel (hexane/EtOAc) to provide the title compound (252 mg, 1.56 mmol) as pale yellow oil in $78 \%$ yield. ${ }^{1} \mathrm{H} \mathrm{NMR}\left(400 \mathrm{MHz}, \mathrm{CDCl}_{3}\right) \delta: 7.55(1 \mathrm{H}, \mathrm{brs}), 4.87$ $(1 \mathrm{H}, \mathrm{m}), 4.86(1 \mathrm{H}, \mathrm{m}), 4.63(1 \mathrm{H}, \mathrm{m}), 3.85(3 \mathrm{H}, \mathrm{s})$.

\section{(RS)-Methyl 2-(2-phenethylbenzylmercapto)oxazoline-4-carboxylate (3a)}

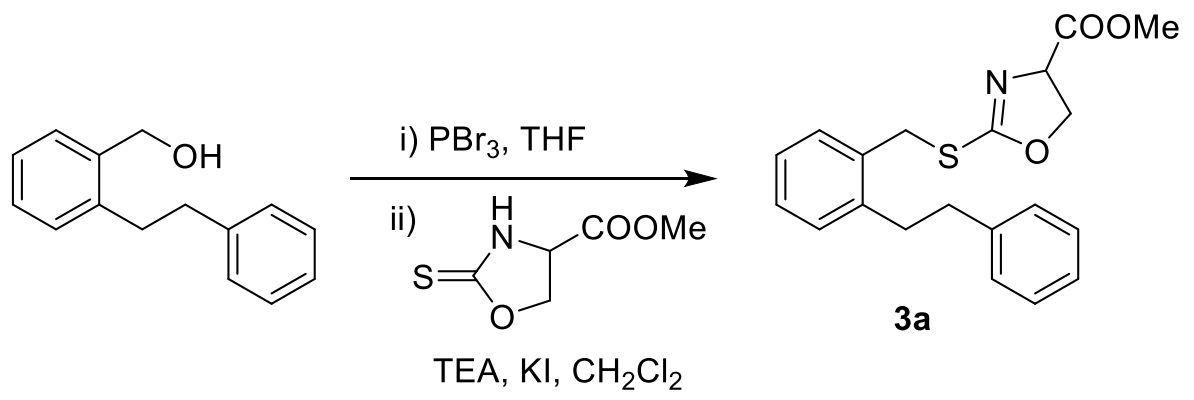

$\mathrm{PBr}_{3}(318 \mu \mathrm{L}, 3.38 \mathrm{mmol})$ was added to a solution of commercially available 2phenethylbenzyl alcohol $(359 \mathrm{mg}, 1.69 \mathrm{mmol})$ in THF $(5 \mathrm{~mL})$ at $0{ }^{\circ} \mathrm{C}$. The mixture was stirred $3 \mathrm{~h}$ at the same temperature. The reaction mixture was poured into ice-water, extracted with EtOAc, washed with sat. $\mathrm{NaCl}$ aq., dried over $\mathrm{MgSO}_{4}$, and evaporated. The resulting residue was added into a solution of $(R S)$-4-methoxycarbonyloxazolidine2-thione (272 $\mathrm{mg}, 1.69 \mathrm{mmol})$ in $\mathrm{CH}_{2} \mathrm{Cl}_{2}(10 \mathrm{~mL})$ containing triethylamine (471 $\mu \mathrm{L}, 3.38$ $\mathrm{mmol}$ ) and $\mathrm{KI}(281 \mathrm{mg}, 1.69 \mathrm{mmol})$. The mixture was refluxed overnight. The reaction mixture was poured into water, extracted with EtOAc, washed with sat. $\mathrm{NaCl}$ aq., dried 
over $\mathrm{MgSO}_{4}$, and evaporated. The resulting residue was purified by column chromatography on silica gel (hexane/EtOAc) to provide the title compound (280 $\mathrm{mg}$, $0.788 \mathrm{mmol})$ as colorless oil in $47 \%$ yield. ${ }^{1} \mathrm{H} \mathrm{NMR}\left(400 \mathrm{MHz}, \mathrm{CDCl}_{3}\right) \delta: 7.36(1 \mathrm{H}, \mathrm{d}, J=$ 7.6 Hz), 7.31-7.28 (2H, m), 7.25-7.15 (6H, m), $4.78(1 \mathrm{H}, \mathrm{dd}, J=10.0 \mathrm{~Hz}, 7.2 \mathrm{~Hz}), 4.62(1 \mathrm{H}$, dd, $J=8.8 \mathrm{~Hz}, 7.2 \mathrm{~Hz}), 4.52(1 \mathrm{H}, \mathrm{dd}, J=10.0 \mathrm{~Hz}, 8.4 \mathrm{~Hz}), 4.34(2 \mathrm{H}, \mathrm{s}), 3.78(3 \mathrm{H}, \mathrm{s}), 3.02-$ $2.90(4 \mathrm{H}, \mathrm{m})$. HRMS (FAB) calcd for $\mathrm{C}_{20} \mathrm{H}_{22} \mathrm{NO}_{3} \mathrm{~S}[\mathrm{M}+\mathrm{H}]+: \mathrm{m} / \mathrm{z} 356.1320$, found 356.1318 .

( $R S$ )-2-Amino-3-(2-phenethylbenzylmercaptocarbonyloxy)propionic acid hydrochloride (4a) by alkaline hydrolysis of $3 a$.<smiles>O=CC1COC(SCc2ccccc2CCc2ccccc2)=N1</smiles>

3a i) $\mathrm{NaOH}, \mathrm{EtOH}, \mathrm{H}_{2} \mathrm{O}$

ii) HClaq.<smiles>NC(COC(=O)SCc1ccccc1CCc1ccccc1)C(=O)O</smiles>

$4 a$

$1 \mathrm{M} \mathrm{NaOH}$ aq. $(5 \mathrm{~mL})$ was added to a solution of $3 \mathbf{a}(200 \mathrm{mg}, 0.563 \mathrm{mmol})$ in EtOH (5 $\mathrm{mL}$ ). The mixture was stirred $2 \mathrm{~h}$ at $40{ }^{\circ} \mathrm{C}$. The reaction mixture was acidified by $10 \%$ $\mathrm{HCl}$ aq., extracted with EtOAc, washed with sat. $\mathrm{NaCl}$ aq., dried over $\mathrm{MgSO}_{4}$, and evaporated. The resulting residue was crystalized by EtOAc to provide the title compound (116 mg, $0.293 \mathrm{mmol}$ ) as colorless solid in 52\% yield. ${ }^{1} \mathrm{H}$ NMR (400 MHz, DMSO- $\left.d_{6}\right) \delta: 8.61$ (2H, brs), 7.34-7.16 (9H, m), $4.60(2 \mathrm{H}, \mathrm{m}), 4.39(1 \mathrm{H}, \mathrm{t}, J=3.2 \mathrm{~Hz}), 4.20$ $(2 \mathrm{H}, \mathrm{s}), 2.94-2.84(4 \mathrm{H}, \mathrm{m})$. HRMS (FAB) calcd for $\mathrm{C}_{19} \mathrm{H}_{22} \mathrm{NO}_{4} \mathrm{~S}[\mathrm{M}+\mathrm{H}]+: \mathrm{m} / z$ 360.1270, found 360.1259 .

\section{(RS)-Methyl 2-benzylmercaptooxazoline-4-carboxylate (3b)}<smiles>CCN(CC)CCOC(C)=O</smiles>

The title compound was synthesized from benzylbromide $(95 \mu \mathrm{L}, 0.80 \mathrm{mmol})$ and $(R S)$ 4-methoxycarbonyloxazolidine-2-thione (100 mg, $0.620 \mathrm{mmol}$ ) by similar manner of synthesis of $\mathbf{3 a}$ as colorless oil. This material was used for the next step without further purification. ${ }^{1} \mathrm{H} \mathrm{NMR}\left(400 \mathrm{MHz} \mathrm{CDCl}_{3}\right)$ 8: 7.37-7.24 $(5 \mathrm{H}, \mathrm{m}), 4.78(1 \mathrm{H}, \mathrm{dd}, J=10.0 \mathrm{~Hz}$, $7.6 \mathrm{~Hz}), 4.61(1 \mathrm{H}, \mathrm{t}, J=8.0 \mathrm{~Hz}), 4.51(1 \mathrm{H}, \mathrm{m}), 4.28(2 \mathrm{H}, \mathrm{s}), 3.79(3 \mathrm{H}, \mathrm{s})$. 
$(R S)$-2-Amino-3-(benzylmercaptocarbonyloxy)propionic acid hydrochloride (4b) by alkaline hydrolysis of $3 b$.

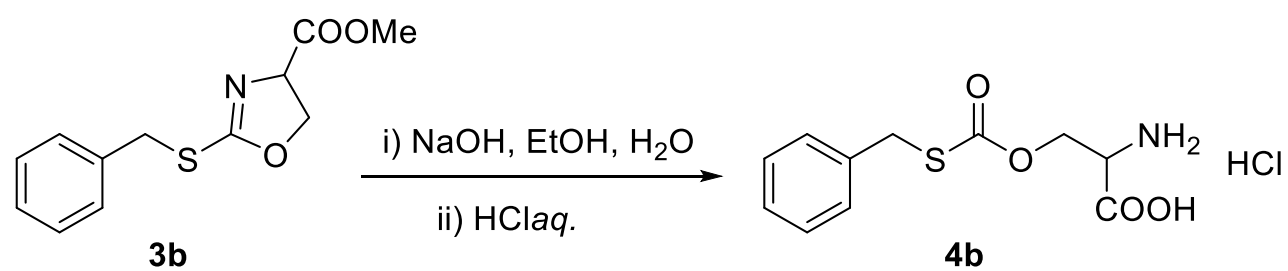

The title compound (79 $\mathrm{mg}, 0.27 \mathrm{mmol}$ ) was synthesized from $3 \mathbf{b}$ by similar manner of synthesis of $4 \mathrm{a}$ as colorless solid in $44 \%$ yield in 2 steps. ${ }^{1} \mathrm{H}$ NMR (400 MHz, DMSO- $d 6$ )

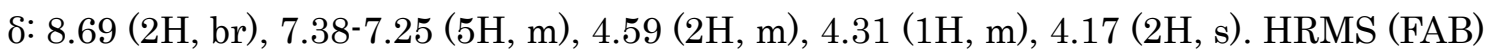
calcd for $\mathrm{C}_{11} \mathrm{H}_{14} \mathrm{NO}_{4} \mathrm{~S}[\mathrm{M}+\mathrm{H}]^{+}: \mathrm{m} / z$ 256.0644, found 256.0646. HPLC: 96\% purity, RT 4.85 $\min (\operatorname{method} \mathrm{B})$.

(RS)-tert-Butyl-(2-butoxycarbonylamino-3-benzylmercaptocarbonyloxy)propionate

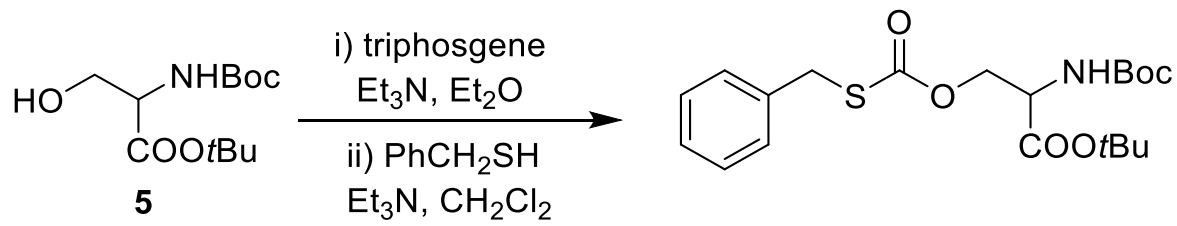

Triphosgene (208 mg, $0.700 \mathrm{mmol})$ was added to a solution of Boc-Ser-O $t \mathrm{Bu} 5$ (261 mg, $1.00 \mathrm{mmol})$ and triethylamine $(97.6 \mu \mathrm{L}, 0.700 \mathrm{mmol})$ in $\mathrm{Et}_{2} \mathrm{O}(5 \mathrm{~mL})$ at $0{ }^{\circ} \mathrm{C}$. The mixture was warmed to room temperature and stirred $10 \mathrm{~h}$. After evaporation, the residue was dissolved in $\mathrm{CH}_{2} \mathrm{Cl}_{2}(1 \mathrm{~mL})$ and added to a solution of benzylmercaptan $(82.2 \mu \mathrm{L}, 0.700$ mmol) and triethylamine $(97.6 \mu \mathrm{L}, 0.700 \mathrm{mmol})$ in $\mathrm{CH}_{2} \mathrm{Cl}_{2}(3 \mathrm{~mL})$. The mixture was stirred overnight at room temperature. The reaction mixture was poured into $\mathrm{H}_{2} \mathrm{O}$, extracted with EtOAc, washed with sat. $\mathrm{NaCl}$ aq., dried over $\mathrm{MgSO}_{4}$, and evaporated. The resulting residue was purified by column chromatography on silica gel (hexane/EtOAc) to provide the title compound (258 $\mathrm{mg}, 0.627 \mathrm{mmol}$ ) as colorless oil in $63 \%$ yield. ${ }^{1} \mathrm{H}$ NMR (400 MHz, DMSO- $\left.d_{6}\right)$ 8: 7.36-7.24 $(5 \mathrm{H}, \mathrm{m}), 4.36(2 \mathrm{H}, \mathrm{m}), 4.20(1 \mathrm{H}$, m), $4.14(2 \mathrm{H}, \mathrm{s}), 1.38(9 \mathrm{H}, \mathrm{s}), 1.37(9 \mathrm{H}, \mathrm{s})$. HRMS (FAB) calcd for $\mathrm{C}_{20} \mathrm{H}_{30} \mathrm{NO}_{6} \mathrm{~S}[\mathrm{M}+\mathrm{H}]+$ : $\mathrm{m} / \mathrm{z} 412.1794$, found 412.1799 .

( $R S$ )-2-Amino-3-(benzylmercaptocarbonyloxy)propionic acid hydrochloride (4b)<smiles>CCOC(=O)C(C)NC(COC(=O)SCc1ccccc1)Cc1cccc(CSC(=O)OCC(N)C(=O)O)c1</smiles> 
$4 \mathrm{M} \mathrm{HCl}$ in EtOAc $(2.5 \mathrm{~mL})$ was added to a solution of $(R S)$-tert-butyl-(2butoxycarbonylamino-3-benzylmercaptocarbonyloxy)propionate (124 mg, $0.301 \mathrm{mmol})$ in $\mathrm{MeOH}(5 \mathrm{~mL})$. The mixture was stirred $4 \mathrm{~h}$ at room temperature and evaporated. The resulting residue was crystalized by EtOAc to provide the title compound $(87 \mathrm{mg}, 0.298$ mmol) as colorless solid in 99\% yield. $\left.{ }^{1} \mathrm{H} \mathrm{NMR} \mathrm{(400} \mathrm{MHz,} \mathrm{DMSO-} d 6\right)$ ) $8.65(2 \mathrm{H}, \mathrm{br})$, 7.38-7.25 (5H, m), $4.60(2 \mathrm{H}, \mathrm{m}), 4.39(1 \mathrm{H}, \mathrm{m}), 4.17(2 \mathrm{H}, \mathrm{s})$. HRMS (FAB) calcd for $\mathrm{C}_{11} \mathrm{H}_{14} \mathrm{NO}_{4} \mathrm{~S}[\mathrm{M}+\mathrm{H}]+: \mathrm{m} / \mathrm{z}$ 256.0644, found 256.0656. HPLC: 95\% purity, RT $4.90 \mathrm{~min}$ (method B).

\section{$O$ (2-tert-Butoxycarbonylamino)ethyl- $S$-benzylcarbonothioate (4e)}<smiles>CC(C)(C)OCCNCCOC(=O)SCc1ccccc1</smiles>

$N$-Boc-ethanolamine $(190 \mu \mathrm{L}, 1.23 \mathrm{mmol})$ was dropwise added to a solution of $N, N^{\text {- }}$ carbonyldiimidazole (221 mg, $1.36 \mathrm{mmol})$ in $\mathrm{CH}_{2} \mathrm{Cl}_{2}(5 \mathrm{~mL})$. After the mixture was stirred $1.5 \mathrm{~h}$ under Ar atmosphere at room temperature, benzyl mercaptan $(170 \mu \mathrm{L}, 1.45 \mathrm{mmol})$ was added. After stirring at room temperature overnight, the reaction mixture was quenched with saturated aqueous $\mathrm{NaCl}$, extracted with $\mathrm{CHCl}_{3}$, dried over $\mathrm{Na}_{2} \mathrm{SO}_{4}$ and evaporated. The resulting residue was purified by column chromatography on silica gel (hexane/EtOAc $=5 / 1)$ to provide the title compound $(328 \mathrm{mg}, 1.05 \mathrm{mmol}$ ) as colorless oil in $85 \%$ yield. ${ }^{1} \mathrm{H}-\mathrm{NMR}\left(400 \mathrm{MHz}, \mathrm{CDCl}_{3}\right) \delta: 7.35-7.25(5 \mathrm{H}, \mathrm{m}), 4.77(1 \mathrm{H}, \mathrm{brs}), 4.28(2 \mathrm{H}, \mathrm{t}$, $J=5.2 \mathrm{~Hz}), 4.11(2 \mathrm{H}, \mathrm{s}), 3.41(2 \mathrm{H}, \mathrm{m}), 1.44(9 \mathrm{H}, \mathrm{s}) . \mathrm{MS}(\mathrm{EI})$ calcd for $\mathrm{C}_{15} \mathrm{H}_{21} \mathrm{NO}_{4} \mathrm{~S}[\mathrm{M}]+$ : $\mathrm{m} / \mathrm{z}$ 311.12, found. 311.13. HPLC: 97\% purity, RT $3.93 \mathrm{~min}$ (method B).

\section{$O$-(2-tert-Butoxycarbonylamino)ethyl- $S$-(2,4-dichlorobenzyl)carbonothioate (4f)}

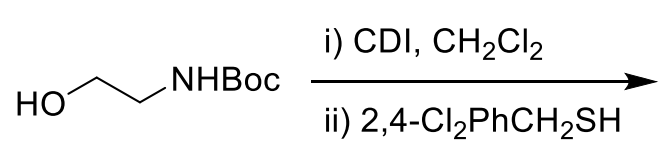<smiles>[14CH3]NCCOC(=O)SCc1ccc(Cl)cc1Cl</smiles>

$N$-Boc-ethanolamine (192 $\mu \mathrm{L}, 1.24 \mathrm{mmol})$ was dropwise added to a solution of $N, N^{\text {- }}$ carbonyldiimidazole $(241 \mathrm{mg}, 1.49 \mathrm{mmol})$ in $\mathrm{CH}_{2} \mathrm{Cl}_{2}(2 \mathrm{~mL})$. After the mixture was stirred $3 \mathrm{~h}$ under Ar atmosphere at room temperature, 2,4-dichlorobenzyl mercaptan $(248 \mu \mathrm{L}$, $1.75 \mathrm{mmol}$ ) was added. After stirring $18 \mathrm{~h}$ at room temperature, the reaction mixture was quenched with $\mathrm{H}_{2} \mathrm{O}$, extracted with $\mathrm{CHCl}_{3}$, dried over $\mathrm{Na}_{2} \mathrm{SO}_{4}$ and evaporated. The resulting residue was purified by column chromatography on silica gel (hexane/EtOAc $=$ 
1/1) to provide the title compound ( $434 \mathrm{mg}, 1.14 \mathrm{mmol}$ ) as colorless solid in $92 \%$ yield. ${ }^{1} \mathrm{H}-\mathrm{NMR}\left(\mathrm{CDCl}_{3}\right)$ 8: $7.43(1 \mathrm{H}, \mathrm{d}, J=7.9 \mathrm{~Hz}), 7.40(1 \mathrm{H}, \mathrm{d}, J=2.4 \mathrm{~Hz}), 7.21(1 \mathrm{H}, \mathrm{m}), 4.76$ (1H, brs), $4.27(2 \mathrm{H}, \mathrm{t}, J=4.8 \mathrm{~Hz}), 4.15(2 \mathrm{H}, \mathrm{s}), 3.40(2 \mathrm{H}, \mathrm{m}), 1.44(9 \mathrm{H}, \mathrm{s}) . \mathrm{MS}$ (EI) calcd for $\mathrm{C}_{15} \mathrm{H}_{19} \mathrm{Cl}_{2} \mathrm{NO}_{4} \mathrm{~S}[\mathrm{M}]^{+}: \mathrm{m} / \mathrm{z} 383.0\left[{ }^{37} \mathrm{Cl}^{37} \mathrm{ClM}\right]^{+}, 381.0\left[{ }^{37} \mathrm{Cl}^{35} \mathrm{ClM}\right]^{+}, 379.0\left[{ }^{[35} \mathrm{Cl}^{35} \mathrm{ClM}\right]^{+}$, found. $383.0\left[{ }^{37} \mathrm{Cl}^{37} \mathrm{ClM}\right]^{+}, 381.0\left[{ }^{37} \mathrm{Cl}^{35} \mathrm{ClM}\right]^{+}, 379.0\left[{ }^{35} \mathrm{Cl}{ }^{35} \mathrm{ClM}\right]^{+}$. HPLC: $96 \%$ purity, $\mathrm{RT}$ $4.48 \min (\operatorname{method} \mathrm{B})$.

$O$-(2-Aminoethyl)-S-benzylcarbonothioate hydrochloride (4c)<smiles>CCOC(=O)COC(=O)SCc1ccccc1</smiles>

$4 \mathrm{M} \mathrm{HCl}$ in 1,4-dioxane $(1.83 \mathrm{~mL}, 7.32 \mathrm{mmol})$ was added to a solution of $4 \mathrm{e}(228 \mathrm{mg}$, $0.732 \mathrm{mmol})$ in EtOAc $(5 \mathrm{~mL})$ at $0{ }^{\circ} \mathrm{C}$. The mixture was stirred $3 \mathrm{~h}$ at room temperature and evaporated. The resulting residue was crystalized by EtOAc to provide the title compound (130 mg, $0.525 \mathrm{mmol}$ ) as colorless solid in $72 \%$ yield. ${ }^{1} \mathrm{H}-\mathrm{NMR}(400 \mathrm{MHz}$, DMSO- $\left.d_{6}\right) \delta: 8.12$ (3H, brs), 7.38-7.32 (5H, m), $4.38(2 \mathrm{H}, \mathrm{t}, J=5.5 \mathrm{~Hz}), 4.18(2 \mathrm{H}, \mathrm{s}), 3.12$ $(2 \mathrm{H}, \mathrm{m})$. MS (EI) calcd for $\mathrm{C}_{10} \mathrm{H}_{13} \mathrm{NO}_{2} \mathrm{~S}[\mathrm{M}]^{+}: \mathrm{m} / \mathrm{z} 211.07$, found 211.08 . HPLC: $96 \%$ purity, RT $2.11 \min (\operatorname{method} B)$.

\section{$O$-(2-Aminoethyl)- $S$ (2,4-dichlorobenzyl)carbonothioate hydrochloride (4d)}

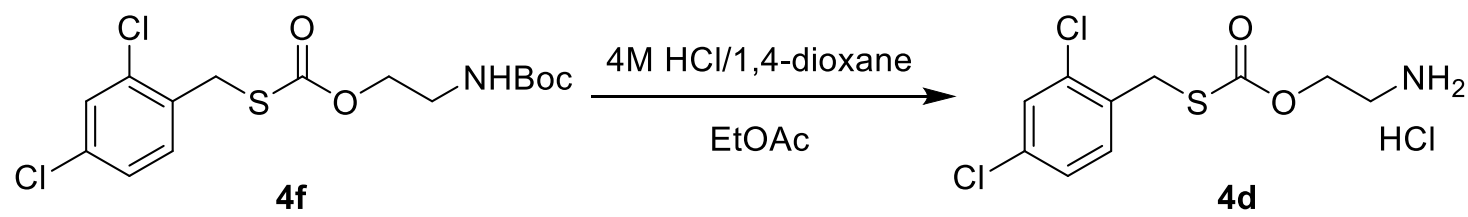

$4 \mathrm{M} \mathrm{HCl}$ in 1,4-dioxane $(2.04 \mathrm{~mL}, 8.16 \mathrm{mmol})$ was added to a solution of $4 \mathrm{f}(207 \mathrm{mg}$, $0.544 \mathrm{mmol})$ in EtOAc $(6 \mathrm{~mL})$ at $0{ }^{\circ} \mathrm{C}$. After the mixture was stirred $19 \mathrm{~h}$ at room temperature, $4 \mathrm{M} \mathrm{HCl}$ in 1,4-dioxane $(680 \mu \mathrm{L}, 2.72 \mathrm{mmol})$ was added. The reaction mixture was stirred $2 \mathrm{~h}$ and evaporated. The resulting residue was crystalized by EtOAc to provide the title compound (89 $\mathrm{mg}, 0.281 \mathrm{mmol}$ ) as colorless solid in $52 \%$ yield. ${ }^{1} \mathrm{H}^{-}$ NMR (DMSO- $\left.d_{6}\right)$ 8: 8.13 (2H, brs), $7.67(1 \mathrm{H}, \mathrm{d}, J=2.4 \mathrm{~Hz}), 7.56(1 \mathrm{H}, \mathrm{d}, J=8.7 \mathrm{~Hz}), 7.44$ $(1 \mathrm{H}, \mathrm{dd}, J=8.3 \mathrm{~Hz}, 2.0 \mathrm{~Hz}), 4.39(2 \mathrm{H}, \mathrm{m}), 4.24(2 \mathrm{H}, \mathrm{s}), 3.11(2 \mathrm{H}, \mathrm{t}, J=5.5 \mathrm{~Hz}) . \mathrm{MS}(\mathrm{EI})$ calcd for $\mathrm{C}_{10} \mathrm{H}_{11} \mathrm{Cl}_{2} \mathrm{NO}_{2} \mathrm{~S}[\mathrm{M}]+:=\mathrm{m} / z \quad 282.98\left[{ }^{37} \mathrm{Cl}^{37} \mathrm{ClM}\right]^{+}, 280.99\left[{ }^{37} \mathrm{Cl}^{35} \mathrm{ClM}\right]^{+}, 278.99$ $\left[{ }^{35} \mathrm{Cl}{ }^{35} \mathrm{ClM}\right]^{+}$, found $282.99\left[{ }^{37} \mathrm{Cl}^{37} \mathrm{ClM}\right]^{+}, 280.99$ [ $\left.^{37} \mathrm{Cl}^{35} \mathrm{ClM}\right]^{+}, 278.99\left[{ }^{35} \mathrm{Cl}^{35} \mathrm{ClM}\right]^{+}$. HPLC: $95 \%$ purity, RT $2.63 \min (\operatorname{method} \mathrm{B})$. 


\section{$S$-Benzyl-1H-imidazole-1-carbothioate}

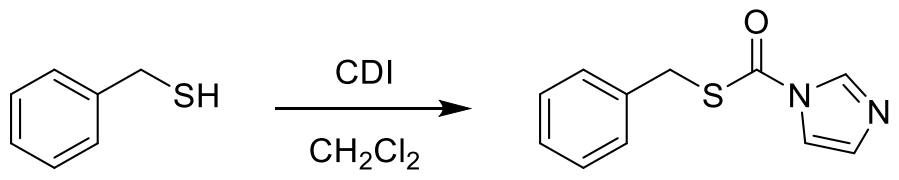

Benzyl mercaptan $(473 \mu \mathrm{L}, 4.03 \mathrm{mmol})$ was dropwise added to a solution of $N, N^{\text {- }}$ carbonyldiimidazole $(789 \mathrm{mg}, 4.87 \mathrm{mmol})$ in $\mathrm{CH}_{2} \mathrm{Cl}_{2}(9 \mathrm{~mL})$. The mixture was stirred 30 min under Ar atmosphere at room temperature. After the evaporation, the resulting residue was purified by column chromatography on silica gel (hexane/EtOAc $=1 / 3$ ) to provide the title compound ( $851 \mathrm{mg}, 3.90 \mathrm{mmol}$ ) as colorless oil in $97 \%$ yield. ${ }^{1} \mathrm{H}-\mathrm{NMR}$ $\left(\mathrm{CDCl}_{3}\right) \delta: 8.18(1 \mathrm{H}, \mathrm{s}), 7.45(1 \mathrm{H}, \mathrm{t}, J=1.6 \mathrm{~Hz}), 7.40-7.30(5 \mathrm{H}, \mathrm{m}), 7.09(1 \mathrm{H}, \mathrm{m}), 4.37(2 \mathrm{H}$, s).

\section{$S^{2}$ 2,4-Dichlorobenzyl-1H-imidazole-1-carbothioate}<smiles>O=C(SCc1ccc(Cl)cc1Cl)n1ccnc1</smiles>

2,4-Dichlorobenzyl mercaptan $(0.17 \mathrm{~mL}, 1.20 \mathrm{mmol})$ was dropwise added to a solution of $N, N$-carbonyldiimidazole (209 $\mathrm{mg}, 1.29 \mathrm{mmol})$ in $\mathrm{CH}_{2} \mathrm{Cl}_{2}(2 \mathrm{~mL})$. The mixture was stirred $1 \mathrm{~h}$ under Ar atmosphere at room temperature. After the evaporation, the resulting residue was purified by column chromatography on silica gel (hexane/EtOAc = $5 / 1$ ) to provide the title compound $(199 \mathrm{mg}, 0.693 \mathrm{mmol})$ as colorless solid in $58 \%$ yield. ${ }^{1} \mathrm{H}-\mathrm{NMR}\left(400 \mathrm{MHz}, \mathrm{CDCl}_{3}\right)$ 8: $8.17(1 \mathrm{H}, \mathrm{s}), 7.49(1 \mathrm{H}, \mathrm{d}, J=8.4 \mathrm{~Hz}), 7.43(1 \mathrm{H}, \mathrm{d}, J=2.0$ $\mathrm{Hz}), 7.43(1 \mathrm{H}, \mathrm{s}), 7.24(1 \mathrm{H}, \mathrm{dd}, J=8.4 \mathrm{~Hz}, 1.6 \mathrm{~Hz}), 7.09(1 \mathrm{H}, \mathrm{d}, J=1.2 \mathrm{~Hz}), 4.42(2 \mathrm{H}, \mathrm{s})$.

\section{$S^{-B e n z y l-} S^{\prime}$ (2-tert-butoxycarbonylamino)ethyldithiocarbonate (5c)}

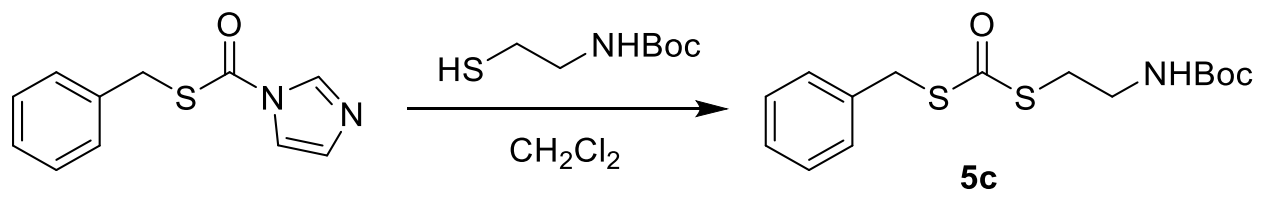

2-(Boc-amino)ethanethiol $(717 \mu \mathrm{L}, 4.24 \mathrm{mmol})$ was added to a solution of $S$-benzyl- $1 H^{-}$ imidazole-1-carbothioate $(771 \mathrm{mg}, 3.53 \mathrm{mmol})$ in $\mathrm{CH}_{2} \mathrm{Cl}_{2}(8 \mathrm{~mL})$. After the mixture was stirred $6 \mathrm{~h}$ under Ar atmosphere at room temperature, 2-(Boc-amino)ethanethiol (299 $\mu \mathrm{L}, 1.77 \mathrm{mmol}$ ) was added. After stirring $17 \mathrm{~h}$ at room temperature, the reaction mixture was quenched with $\mathrm{H}_{2} \mathrm{O}$, extracted with $\mathrm{CHCl}_{3}$, dried over $\mathrm{Na}_{2} \mathrm{SO}_{4}$ and evaporated. The resulting residue was purified by column chromatography on silica gel $\left(\mathrm{CHCl}_{3}\right)$ to provide 
the crude title compound. Crystallization by hexane afforded the title compound (102 mg, $0.311 \mathrm{mmol})$ as colorless solid in 9\% yield. ${ }^{1} \mathrm{H}-\mathrm{NMR}\left(\mathrm{CDCl}_{3}\right)$ 8: 7.33-7.24 $(5 \mathrm{H}, \mathrm{m}), 4.83$ $(1 \mathrm{H}, \mathrm{br}), 4.23(2 \mathrm{H}, \mathrm{s}), 3.35(2 \mathrm{H}, \mathrm{q}, \mathrm{J}=5.9 \mathrm{~Hz}), 3.13(2 \mathrm{H}, \mathrm{t}, \mathrm{J}=6.3 \mathrm{~Hz}), 1.44(9 \mathrm{H}, \mathrm{s}) . \mathrm{MS}$ (EI) calcd for $\mathrm{C}_{15} \mathrm{H}_{21} \mathrm{NO}_{3} \mathrm{~S}_{2}[\mathrm{M}]+: \mathrm{m} / z$ 327.10, found 327.17. HPLC: 99\% purity, RT 6.97 $\min (\operatorname{method} \mathrm{B})$.

\section{$S$-(2-Aminoethyl)- $S$-benzyldithiocarbonate hydrochloride (5a)}<smiles>CCOC(=O)CCCC(C)(C)C(C)(C)C</smiles>

$4 \mathrm{M} \mathrm{HCl}$ in 1,4-dioxane $(344 \mu \mathrm{L}, 1.38 \mathrm{mmol})$ was added to a solution of $5 \mathrm{c}(100 \mathrm{mg}$, $0.311 \mathrm{mmol})$ in EtOAc $(5 \mathrm{~mL})$ at $0{ }^{\circ} \mathrm{C}$. After the mixture was stirred $22 \mathrm{~h}$ at room temperature, $4 \mathrm{M} \mathrm{HCl}$ in 1,4-dioxane $(344 \mu \mathrm{L}, 1.38 \mathrm{mmol})$ was added. After the mixture was stirred $10 \mathrm{~h}$ at room temperature, $4 \mathrm{M} \mathrm{HCl}$ in 1,4-dioxane $(172 \mu \mathrm{L}, 0.688 \mathrm{mmol})$ was added. The reaction mixture was stirred $16 \mathrm{~h}$ and evaporated. The resulting residue was crystalized by EtOAc to provide the title compound ( $46 \mathrm{mg}, 0.174 \mathrm{mmol}$ ) as colorless solid in 56\% yield. ${ }^{1} \mathrm{H}-\mathrm{NMR}$ (DMSO- $\left.d_{6}\right)$ 8: $8.19(2 \mathrm{H}, \mathrm{brs}), 7.35-7.31(4 \mathrm{H}, \mathrm{m}), 7.28(1 \mathrm{H}, \mathrm{m}), 4.31$ $(2 \mathrm{H}, \mathrm{s}), 3.26(2 \mathrm{H}, \mathrm{t}, J=7.1 \mathrm{~Hz}), 3.00(2 \mathrm{H}, \mathrm{t}, J=7.1 \mathrm{~Hz})$. MS (EI) calcd for $\mathrm{C}_{10} \mathrm{H}_{13} \mathrm{NOS}_{2}$ [M]+: $\mathrm{m} / \mathrm{z} 227.04$, found 227.03. HPLC: 97\% purity, RT $5.18 \mathrm{~min}$ (method B).

\section{$S^{-(2-t e r t-B u t o x y c a r b o n y l a m i n o) e t h y l-} S^{\prime}$ (2,4-dichlorobenzyl)dithiocarbonate (5d)}<smiles>CC(C)(C)NCCCNC(=O)OCc1ccccc1</smiles>

2-(Boc-amino)ethanethiol $(730 \mu \mathrm{L}, 4.32 \mathrm{mmol})$ was added to a solution of $S^{-2,4}$ dichlorobenzyl-1H-imidazole-1-carbothioate $(1029 \mathrm{mg}, 3.58 \mathrm{mmol})$ in $\mathrm{CHCl}_{3}(10 \mathrm{~mL})$. The mixture was stirred $1 \mathrm{~h}$ under Ar atmosphere at room temperature. After the evaporation, the resulting residue was purified by column chromatography on silica gel (hexane/EtOAc $=3 / 1$ ) to provide the crude title compound. Crystallization by hexane afforded the title compound (508 mg, $1.28 \mathrm{mmol}$ as colorless solid in $36 \%$ yield. ${ }^{1} \mathrm{H}-\mathrm{NMR}$ $\left(\mathrm{CDCl}_{3}\right)$ 8: $7.39(1 \mathrm{H}, \mathrm{d}, J=1.6 \mathrm{~Hz}), 7.38(1 \mathrm{H}, \mathrm{d}, J=8.0 \mathrm{~Hz}), 7.20(1 \mathrm{H}, \mathrm{dd}, J=8.4 \mathrm{~Hz}, 2.0$ $\mathrm{Hz}), 4.81(1 \mathrm{H}, \mathrm{br}), 4.28(2 \mathrm{H}, \mathrm{s}), 3.34(2 \mathrm{H}, \mathrm{q}, J=6.4 \mathrm{~Hz}), 3.13(2 \mathrm{H}, \mathrm{t}, J=6.4 \mathrm{~Hz}), 1.44(9 \mathrm{H}$, s). $\mathrm{MS}$ (EI) calcd for $\mathrm{C}_{15} \mathrm{H}_{19} \mathrm{Cl}_{2} \mathrm{NO}_{3} \mathrm{~S}_{2}[\mathrm{M}]^{+:} \mathrm{m} / z$ 397.02 $\left[{ }^{37} \mathrm{Cl}^{35} \mathrm{ClM}\right]^{+}, 395.02\left[{ }^{35} \mathrm{Cl}^{35} \mathrm{ClM}\right]^{+}$, found $397.00\left[{ }^{37} \mathrm{Cl}^{35} \mathrm{ClM}\right]+, 395.00\left[{ }^{35} \mathrm{Cl}^{35} \mathrm{ClM}\right]+$. HPLC: $98 \%$ purity, RT $7.44 \mathrm{~min}$ (method 
B).

$S$ (2-Aminoethyl)- $S$-2,4-dichlorobenzyldithiocarbonate hydrochloride (5b)

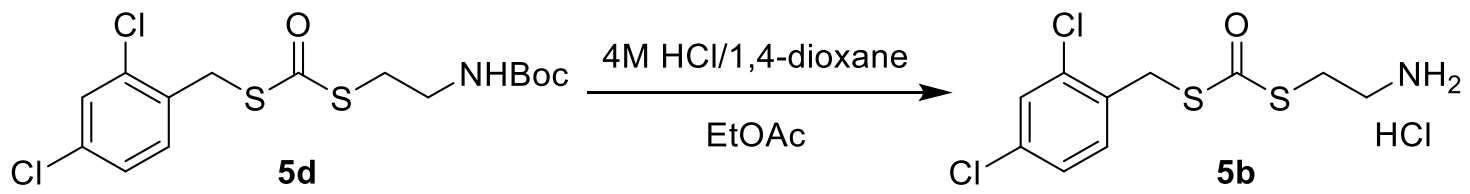

$4 \mathrm{M} \mathrm{HCl}$ in 1,4-dioxane $(1.28 \mathrm{~mL}, 5.12 \mathrm{mmol})$ was added to a solution of $5 \mathrm{~d}(135 \mathrm{mg}$, $0.341 \mathrm{mmol})$ in EtOAc $(8 \mathrm{~mL})$ at $0{ }^{\circ} \mathrm{C}$. After the mixture was stirred $2 \mathrm{~h}$ at room temperature, $4 \mathrm{M} \mathrm{HCl}$ in 1,4-dioxane $(85 \mathrm{\mu L}, 0.34 \mathrm{mmol}$ ) was added. The reaction mixture was stirred $3 \mathrm{~h}$ and evaporated. The resulting residue was crystalized by EtOAc to provide the title compound ( $80 \mathrm{mg}, 0.24 \mathrm{mmol}$ ) as colorless solid in $70 \%$ yield. ${ }^{1} \mathrm{H}-\mathrm{NMR}$ (DMSO- $\left.d_{6}\right)$ 8: 8.17 (2H, brs), $7.66(1 \mathrm{H}, \mathrm{d}, J=2.0 \mathrm{~Hz}), 7.53(1 \mathrm{H}, \mathrm{d}, J=8.3 \mathrm{~Hz}), 7.44(1 \mathrm{H}$, $\mathrm{dd}, J=8.3 \mathrm{~Hz}, 2.0 \mathrm{~Hz}), 4.38(2 \mathrm{H}, \mathrm{s}), 3.26(2 \mathrm{H}, \mathrm{t}, J=7.1 \mathrm{~Hz}), 3.00(2 \mathrm{H}, \mathrm{t}, J=7.1 \mathrm{~Hz}) . \mathrm{MS}$ (EI) calcd for $\mathrm{C}_{10} \mathrm{H}_{11} \mathrm{Cl}_{2} \mathrm{NOS}_{2}[\mathrm{M}]+:$ m/z $299.0\left[{ }^{37} \mathrm{Cl}{ }^{37} \mathrm{ClM}\right]^{+}, 297.0\left[{ }^{37} \mathrm{Cl}{ }^{35} \mathrm{ClM}\right]^{+}, 295.0$ $\left[{ }^{35} \mathrm{Cl}^{35} \mathrm{ClM}\right]^{+}$, found $299.1\left[{ }^{37} \mathrm{Cl}^{37} \mathrm{ClM}\right]^{+}, 297.1\left[{ }^{37} \mathrm{Cl}^{35} \mathrm{ClM}\right]^{+}, 295.1\left[{ }^{35} \mathrm{Cl}^{35} \mathrm{ClM}\right]^{+}$. HRMS (EI) calcd for $\mathrm{C}_{10} \mathrm{H}_{11} \mathrm{Cl}_{2} \mathrm{NOS}_{2}\left[{ }^{35} \mathrm{Cl}^{35} \mathrm{ClM}\right]+:: \mathrm{m} / z$ 294.9659, found 294.9684. HPLC: $98 \%$ purity, RT 5.67 min (method B).

\section{2-tert-Butyldimethylsilyloxyethanethiol}

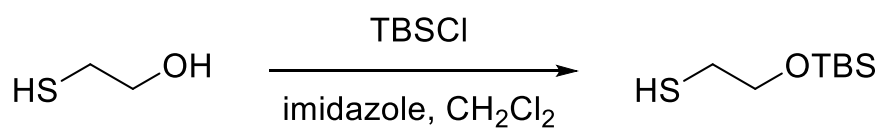

A solution of TBSCl (424 mg, $2.81 \mathrm{mmol}$ ) and imidazole (418 mg, $6.14 \mathrm{mmol})$ in $\mathrm{CH}_{2} \mathrm{Cl}_{2}$ $(4 \mathrm{~mL})$ was dropwise added to a solution of 2 -mercaptoethanol $(200 \mathrm{mg}, 2.56 \mathrm{mmol})$ in $\mathrm{CH}_{2} \mathrm{Cl}_{2}(5 \mathrm{~mL})$. After stirring $10 \mathrm{~min}$ at room temperature, the reaction mixture was quenched with sat. $\mathrm{NaCl} a q$, extracted with $\mathrm{CHCl}_{3}$, dried over $\mathrm{Na}_{2} \mathrm{SO}_{4}$ and evaporated. The resulting residue was purified by column chromatography on silica gel (hexane/EtOAc $=19 / 1)$ to provide the title compound $(241 \mathrm{mg}, 1.25 \mathrm{mmol})$ as colorless oil in $49 \%$ yield. ${ }^{1} \mathrm{H}-\mathrm{NMR}\left(400 \mathrm{MHz}, \mathrm{CDCl}_{3}\right) \delta: 3.73(2 \mathrm{H}, \mathrm{t}, J=6.3 \mathrm{~Hz}), 2.63(2 \mathrm{H}, \mathrm{m}), 1.54$ $(1 \mathrm{H}, \mathrm{m}), 0.91(9 \mathrm{H}, \mathrm{s}), 0.08(6 \mathrm{H}, \mathrm{s})$.

\section{$S$-2,4-Dichlorobenzyl- $S^{\prime 2}$-hydroxyethyldithiocarbonate (5e)}


<smiles>O=C(SCc1ccc(Cl)cc1Cl)n1ccnc1</smiles><smiles>O=C(SCCO)SCc1ccc(Cl)cc1Cl</smiles>

$S$-2,4-dichlorobenzyl-1 $H$-imidazole-1-carbothioate ( $149 \mathrm{mg}, 0.52 \mathrm{mmol})$ was added to a solution of 2-tert-butyldimethylsilyloxyethanethiol(100 mg, $0.52 \mathrm{mmol})$ in $\mathrm{CH}_{2} \mathrm{Cl}_{2}(5 \mathrm{~mL})$. The mixture was stirred $16 \mathrm{~h}$ at room temperature. After the evaporation, the resulting residue was purified by flash column chromatography on silica gel (EtOAc in hexane 0\% to $50 \%)$ to provide $S-2,4$-dichlorobenzyl- $S$-2-tert-butyldimethylsilyloxyethyldithiocarbonate $(166 \mathrm{mg})$ as colorless oil. $4 \mathrm{M} \mathrm{HCl}$ in 1,4-dioxane (1.74 $\mathrm{mL}, 6.96 \mathrm{mmol})$ was added to a solution of $S-2,4$-dichlorobenzyl- $S$-2-tert-butyldimethylsilyloxyethyldithiocarbonate $(166 \mathrm{mg})$ in 1,4 -dioxane $(3 \mathrm{~mL})$ at $0{ }^{\circ} \mathrm{C}$. After stirring overnight at room temperature and evaporation, the residue was extracted with $\mathrm{CHCl}_{3}{ }^{-}$sat $\mathrm{NaCl}$ aq., dried over $\mathrm{Na}_{2} \mathrm{SO}_{4}$ and evaporated. The resulting residue was purified by flash column chromatography on silica gel (hexane/EtOAc $=10 / 1)$ to provide the title compound (54 $\mathrm{mg}, 0.18 \mathrm{mmol}$ ) as colorless oil in $35 \%$ yield (2 steps). ${ }^{1} \mathrm{H}-\mathrm{NMR}\left(400 \mathrm{MHz}, \mathrm{CDCl}_{3}\right)$ 8: 7.39 $(1 \mathrm{H}, \mathrm{d}, J=2.0 \mathrm{~Hz}), 7.38(1 \mathrm{H}, \mathrm{d}, J=8.7 \mathrm{~Hz}), 7.20(1 \mathrm{H}, \mathrm{dd}, J=8.3 \mathrm{~Hz}, 2.0 \mathrm{~Hz}), 4.28(2 \mathrm{H}$, s), $3.81(2 \mathrm{H}, \mathrm{q}, J=6.3 \mathrm{~Hz}), 3.20(2 \mathrm{H}, \mathrm{t}, J=5.9 \mathrm{~Hz}), 1.84(1 \mathrm{H}, \mathrm{t}, J=5.9 \mathrm{~Hz})$. MS (EI) calcd for $\mathrm{C}_{10} \mathrm{H}_{10} \mathrm{Cl}_{2} \mathrm{O}_{2} \mathrm{~S}_{2}[\mathrm{M}]^{+}: \mathrm{m} / z 297.95\left[{ }^{[37} \mathrm{Cl}^{35} \mathrm{ClM}\right]^{+}, 295.95\left[{ }^{35} \mathrm{Cl}^{35} \mathrm{ClM}\right]^{+}$, found 297.99 $\left.{ }^{[37} \mathrm{Cl}^{35} \mathrm{ClM}\right]^{+}, 295.99\left[{ }^{35} \mathrm{Cl}^{35} \mathrm{ClM}\right]^{+}$. HPLC: 99\% purity, RT $6.74 \min (\operatorname{method} \mathrm{B})$.

\section{$S$-Benzyl- $S^{\prime}$-3-hydroxyphenyldithiocarbonate (5f)}<smiles>O=C(SCc1ccccc1)n1ccnc1</smiles><smiles>Oc1cccc(S)c1</smiles><smiles>O=C(SCc1ccccc1)Sc1cccc(O)c1</smiles>

3-Mercaptophenol (84 mg, $0.67 \mathrm{mmol})$ in $\mathrm{CH}_{2} \mathrm{Cl}_{2}(1 \mathrm{~mL})$ was slowly added to a solution of $S$-benzyl-1H-imidazole-1-carbothioate (159 mg, $0.728 \mathrm{mmol})$ in $\mathrm{CH}_{2} \mathrm{Cl}_{2}(2 \mathrm{~mL})$. The mixture was stirred $21 \mathrm{~h}$ at room temperature. After the evaporation, the resulting residue was purified by flash column chromatography on silica gel (EtOAc in hexane 0\% to $33 \%)$ to provide the title compound $(191 \mathrm{mg}, 0.691 \mathrm{mmol})$ as colorless solid in $95 \%$ yield. ${ }^{1} \mathrm{H}-\mathrm{NMR}\left(400 \mathrm{MHz}, \mathrm{CDCl}_{3}\right)$ $8: 7.33-7.24(6 \mathrm{H}, \mathrm{m}), 7.10(1 \mathrm{H}, \mathrm{m}), 7.01(1 \mathrm{H}, \mathrm{dd}, J=2.7$ $\mathrm{Hz}, 1.8 \mathrm{~Hz}), 6.91(1 \mathrm{H}, \mathrm{m}), 5.08(1 \mathrm{H}, \mathrm{s}), 4.20(2 \mathrm{H}, \mathrm{s})$. MS (EI) calcd for $\mathrm{C}_{14} \mathrm{H}_{12} \mathrm{O}_{2} \mathrm{~S}_{2}[\mathrm{M}]+$ : $\mathrm{m} / \mathrm{z} 276.03$, found 276.02. HPLC: 98\% purity, RT $6.79 \mathrm{~min}$ (method B).

\section{$S-2,4$-Dichlorobenzyl- $S^{\prime}$-3-hydroxyphenyldithiocarbonate (5g)}


<smiles>O=C(SCc1ccc(Cl)cc1Cl)n1ccnc1</smiles><smiles>Oc1cccc(S)c1</smiles><smiles>O=C(SCc1ccc(Cl)cc1Cl)Sc1cccc(O)c1</smiles>

3-Mercaptophenol (83mg, $0.66 \mathrm{mmol})$ in $\mathrm{CH}_{2} \mathrm{Cl}_{2}(1 \mathrm{~mL})$ was slowly added to a solution of $S$-2,4-dichlorobenzyl-1H-imidazole-1-carbothioate $(208 \mathrm{mg}, 0.724 \mathrm{mmol})$ in $\mathrm{CH}_{2} \mathrm{Cl}_{2}$ (3 $\mathrm{mL}$ ). The mixture was stirred $24 \mathrm{~h}$ at room temperature. After the evaporation, the resulting residue was purified by flash column chromatography on silica gel (EtOAc in hexane $0 \%$ to $40 \%$ ) to provide the title compound (140 mg, $0.406 \mathrm{mmol}$ ) as colorless solid in $56 \%$ yield. ${ }^{1} \mathrm{H}-\mathrm{NMR}\left(400 \mathrm{MHz}, \mathrm{CDCl}_{3}\right) \delta: 7.38-7.36(2 \mathrm{H}, \mathrm{m}), 7.30(1 \mathrm{H}, \mathrm{t}, J=8.2 \mathrm{~Hz})$, $7.18(1 \mathrm{H}, \mathrm{dd}, J=8.3 \mathrm{~Hz}, 2.3 \mathrm{~Hz}), 7.08(1 \mathrm{H}, \mathrm{dd}, J=7.8 \mathrm{~Hz}, 0.9 \mathrm{~Hz}), 7.00(1 \mathrm{H}, \mathrm{t}, J=2.3$ $\mathrm{Hz}), 6.93(1 \mathrm{H}, \mathrm{m}), 5.00(1 \mathrm{H}, \mathrm{s}), 4.25(2 \mathrm{H}, \mathrm{s})$. MS (EI) calcd for $\mathrm{C}_{14} \mathrm{H}_{10} \mathrm{Cl}_{2} \mathrm{O}_{2} \mathrm{~S}_{2}[\mathrm{M}]+: \mathrm{m} / z$ $345.95\left[{ }^{37} \mathrm{Cl}^{35} \mathrm{ClM}\right]^{+}, 343.95\left[{ }^{35} \mathrm{Cl}^{35} \mathrm{ClM}\right]^{+}$, found $345.95\left[{ }^{37} \mathrm{Cl}^{35} \mathrm{ClM}\right]^{+}, 343.96\left[{ }^{35} \mathrm{Cl}^{35} \mathrm{ClM}\right]^{+}$. HPLC: 96\% purity, RT 7.29 min (method B).

\section{$S^{-B e n z y l-} S^{\prime 2}$-hydroxyphenyldithiocarbonate (5h)}<smiles>O=C(SCc1ccccc1)SCc1ccc(O)cc1</smiles>

4-Mercaptophenol (76 mg, $0.60 \mathrm{mmol}$ ) was slowly added to a solution of $S$-benzyl-1 $H^{-}$ imidazole-1-carbothioate (144 mg, $0.66 \mathrm{mmol})$ in $\mathrm{CH}_{2} \mathrm{Cl}_{2}(2 \mathrm{~mL})$. The mixture was stirred $21 \mathrm{~h}$ at room temperature. After the evaporation, the resulting residue was purified by column chromatography on silica gel (hexane/EtOAc $=7 / 1$ to $6 / 1$ ) to provide the title compound (97 mg, $0.35 \mathrm{mmol}$ ) as colorless solid in $53 \%$ yield. ${ }^{1} \mathrm{H}-\mathrm{NMR}\left(400 \mathrm{MHz}, \mathrm{CDCl}_{3}\right.$ ) 8: $7.39(2 \mathrm{H}, \mathrm{d}, J=9.0 \mathrm{~Hz}), 7.31-7.23(5 \mathrm{H}, \mathrm{m}), 6.84(2 \mathrm{H}, \mathrm{d}, J=8.6 \mathrm{~Hz}), 5.38(1 \mathrm{H}, \mathrm{s}), 4.17$ $(2 \mathrm{H}, \mathrm{s})$. MS (EI) calcd for $\mathrm{C}_{14} \mathrm{H}_{12} \mathrm{O}_{2} \mathrm{~S}_{2}[\mathrm{M}]+: \mathrm{m} / z$ 276.03, found 276.02. HPLC: $98 \%$ purity, RT $6.74 \min (\operatorname{method} \mathrm{B})$.

\section{$S$ 2,4-Dichlorobenzyl- $S^{\prime}$-4-hydroxyphenyldithiocarbonate (5i)}<smiles>O=C(SCc1ccc(Cl)cc1Cl)n1ccnc1</smiles><smiles>Oc1ccc(S)cc1</smiles><smiles>O=C(SCc1ccc(Cl)cc1Cl)Sc1ccc(O)cc1</smiles>

4-Mercaptophenol (103 $\mathrm{mg}, 0.816 \mathrm{mmol}$ ) was slowly added to a solution of $S^{-2,4^{-}}$ 
dichlorobenzyl-1 $1 H$-imidazole-1-carbothioate $(207 \mathrm{mg}, 0.721 \mathrm{mmol})$ in $\mathrm{CH}_{2} \mathrm{Cl}_{2}(4 \mathrm{~mL})$. The mixture was stirred $15 \mathrm{~h}$ at room temperature. After the evaporation, the resulting residue was purified flash column chromatography on silica gel (EtOAc in hexane 0\% to $50 \%$ ) to provide the title compound $(79 \mathrm{mg}, 0.23 \mathrm{mmol}$ ) as colorless solid in $32 \%$ yield. ${ }^{1} \mathrm{H}-\mathrm{NMR}\left(400 \mathrm{MHz}, \mathrm{CDCl}_{3}\right)$ 8: 7.39-7.35 (3H, m), $7.17(1 \mathrm{H}, \mathrm{dd}, J=8.2 \mathrm{~Hz}, 1.8 \mathrm{~Hz}), 6.88$ $(2 \mathrm{H}, \mathrm{d}, J=8.6 \mathrm{~Hz}), 6.00(1 \mathrm{H}, \mathrm{br}), 4.21(2 \mathrm{H}, \mathrm{s})$. MS (EI) calcd for $\mathrm{C}_{14} \mathrm{H}_{10} \mathrm{Cl}_{2} \mathrm{O}_{2} \mathrm{~S}_{2}[\mathrm{M}]+: \mathrm{m} / z$ $347.94\left[{ }^{37} \mathrm{Cl}^{37} \mathrm{ClM}\right]^{+}, 345.95\left[{ }^{37} \mathrm{Cl}^{35} \mathrm{ClM}\right]^{+}, 343.95\left[{ }^{35} \mathrm{Cl}^{35} \mathrm{ClM}\right]^{+}$, found $347.94\left[{ }^{37} \mathrm{Cl}^{37} \mathrm{ClM}\right]^{+}$, $345.93{ }^{\left[{ }^{37} \mathrm{Cl}^{35} \mathrm{ClM}\right]^{+},} 343.95 \quad\left[{ }^{35} \mathrm{Cl}^{35} \mathrm{ClM}\right]^{+}$. HRMS (EI) calcd for $\mathrm{C}_{14} \mathrm{H}_{10} \mathrm{Cl}_{2} \mathrm{O}_{2} \mathrm{~S}_{2}$ [35 $\left.\mathrm{Cl}^{35} \mathrm{ClM}\right]+: \mathrm{m} / \mathrm{z} 343.9499$, found 343.9500. HPLC: 96\% purity, RT $7.27 \mathrm{~min}$ (method B).

\section{4-Mercaptobenzyl alcohol}

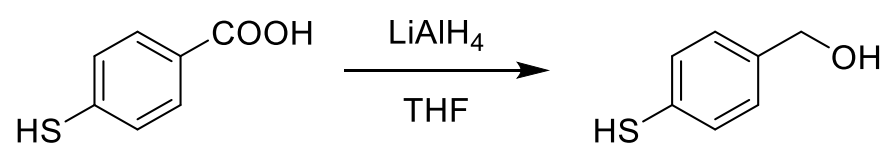

4-Mercaptobenzoic acid (200 mg, $1.30 \mathrm{mmol})$ in THF (4 mL) was slowly added to a suspension of lithium aluminium hydride $(148 \mathrm{mg}, 3.90 \mathrm{mmol})$ in THF $(4 \mathrm{~mL})$ at $0{ }^{\circ} \mathrm{C}$.

After stirring $2 \mathrm{~h}$ at the same temperature, the reaction mixture was quenched with water and $1 \mathrm{M} \mathrm{HCl}$ aq, extracted with EtOAc, dried over $\mathrm{Na}_{2} \mathrm{SO}_{4}$ and evaporated. The resulting residue was purified by column chromatography on silica gel (hexane/EtOAc $=$ $5 / 1$ ) to provide the title compound $(100 \mathrm{mg}, 0.713 \mathrm{mmol}$ ) as colorless solid in $55 \%$ yield. ${ }^{1} \mathrm{H}-\mathrm{NMR}\left(400 \mathrm{MHz}, \mathrm{DMSO}-d_{6}\right)$ 8: $7.24(2 \mathrm{H}, \mathrm{d}, J=8.7 \mathrm{~Hz}), 7.19(2 \mathrm{H}, \mathrm{d}, J=8.7 \mathrm{~Hz}), 5.31$ (1H, brs), $5.13(1 \mathrm{H}, \mathrm{m}), 4.42(2 \mathrm{H}, \mathrm{d}, J=4.8 \mathrm{~Hz})$.

\section{$S$-2,4-Dichlorobenzyl- $S^{\prime}$-4-hydroxymethylphenyldithiocarbonate (5j)}

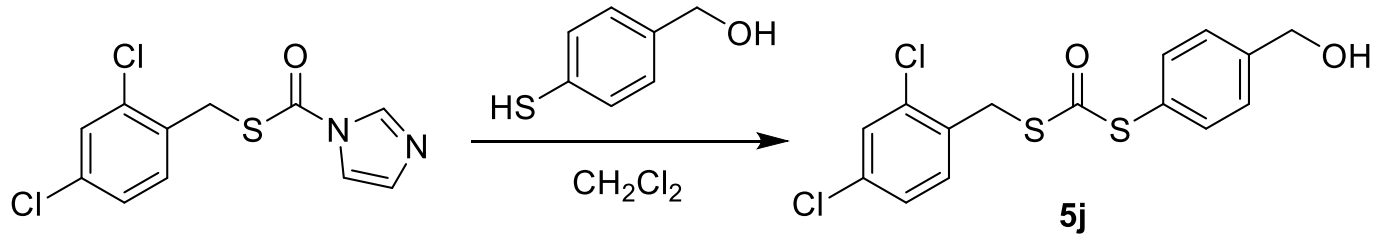

4-Mercaptobenzyl alcohol (100 mg, $0.713 \mathrm{mmol}$ ) was added to a solution of $S^{-2,4}$ dichlorobenzyl-1H-imidazole-1-carbothioate $(204 \mathrm{mg}, 0.710 \mathrm{mmol})$ in $\mathrm{CH}_{2} \mathrm{Cl}_{2}(3 \mathrm{~mL})$. The mixture was stirred $19 \mathrm{~h}$ at room temperature. After the evaporation, the resulting residue was purified by column chromatography on silica gel (hexane/EtOAc $=7 / 1$ ) to provide the title compound ( $194 \mathrm{mg}, 0.540 \mathrm{mmol}$ ) as colorless solid in $76 \%$ yield. ${ }^{1} \mathrm{H}-\mathrm{NMR}$ $\left(400 \mathrm{MHz}, \mathrm{CDCl}_{3}\right)$ 8: $7.50(2 \mathrm{H}, \mathrm{d}, J=8.7 \mathrm{~Hz}), 7.43(2 \mathrm{H}, \mathrm{d}, J=8.7 \mathrm{~Hz}), 7.37(1 \mathrm{H}, \mathrm{d}, J=1.6$ $\mathrm{Hz}), 7.36(1 \mathrm{H}, \mathrm{d}, J=8.3 \mathrm{~Hz}), 7.17(1 \mathrm{H}, \mathrm{dd}, J=8.3 \mathrm{~Hz}, 2.0 \mathrm{~Hz}), 4.75(2 \mathrm{H}, \mathrm{d}, J=4.8 \mathrm{~Hz})$, $4.23(2 \mathrm{H}, \mathrm{s}), 1.78(1 \mathrm{H}, \mathrm{m})$. MS (EI) calcd for $\mathrm{C}_{15} \mathrm{H}_{12} \mathrm{Cl}_{2} \mathrm{O}_{2} \mathrm{~S}_{2}[\mathrm{M}]+: \mathrm{m} / z 359.96\left[{ }^{37} \mathrm{Cl}^{35} \mathrm{ClM}\right]^{+}$, 
$357.97\left[{ }^{35} \mathrm{Cl}^{35} \mathrm{ClM}\right]^{+}$, found $359.79\left[{ }^{37} \mathrm{Cl}^{35} \mathrm{ClM}\right]^{+}, 357.98\left[{ }^{35} \mathrm{Cl}^{35} \mathrm{ClM}\right]^{+}$. HPLC: $98 \%$ purity, RT 7.16 min (method B).

\section{$S$-2,4-Dichlorobenzyl- $S^{\prime}$-4-methoxyphenyldithiocarbonate (5k)}<smiles>COc1ccc(SC(=O)SCc2ccc(Cl)cc2Cl)cc1</smiles>

4-Methoxybenzenethiol ( $60 \mu \mathrm{L}, 0.49 \mathrm{mmol})$ was dropwise added to a solution of $S^{-2,4-}$ dichlorobenzyl-1H-imidazole-1-carbothioate ( $150 \mathrm{mg}, 0.522 \mathrm{mmol})$ in $\mathrm{CH}_{2} \mathrm{Cl}_{2}(5 \mathrm{~mL}$ ). The mixture was stirred overnight at room temperature. After the evaporation, the resulting residue was purified by column chromatography on silica gel (hexane) to provide the title compound (55 mg, $0.15 \mathrm{mmol})$ as colorless oil in $29 \%$ yield. ${ }^{1} \mathrm{H}-\mathrm{NMR}\left(400 \mathrm{MHz}, \mathrm{CDCl}_{3}\right)$ 8: $7.42(2 \mathrm{H}, \mathrm{d}, J=8.7 \mathrm{~Hz}), 7.35(1 \mathrm{H}, \mathrm{d}, J=7.9 \mathrm{~Hz}), 7.35(1 \mathrm{H}, \mathrm{d}, J=2.0 \mathrm{~Hz}), 7.15(1 \mathrm{H}, \mathrm{dd}$, $J=8.3 \mathrm{~Hz}, 2.0 \mathrm{~Hz}), 6.93(2 \mathrm{H}, \mathrm{m}), 4.20(2 \mathrm{H}, \mathrm{s}), 3.83(3 \mathrm{H}, \mathrm{s}) . \mathrm{MS}(\mathrm{EI})$ calcd for $\mathrm{C}_{15} \mathrm{H}_{12} \mathrm{Cl}_{2} \mathrm{O}_{2} \mathrm{~S}_{2}$ $[\mathrm{M}]+: \mathrm{m} / \mathrm{z} 361.96\left[{ }^{[37} \mathrm{Cl}^{37} \mathrm{ClM}\right]^{+}, 359.96\left[{ }^{[37} \mathrm{Cl}^{35} \mathrm{ClM}\right]^{+}, 357.97\left[{ }^{35} \mathrm{Cl}^{35} \mathrm{ClM}\right]^{+}$, found 361.94 $\left[{ }^{37} \mathrm{Cl}^{37} \mathrm{ClM}\right]^{+}, 359.95\left[{ }^{37} \mathrm{Cl}^{35} \mathrm{ClM}\right]^{+}, 357.95\left[{ }^{35} \mathrm{Cl}^{35} \mathrm{ClM}\right]^{+}$. HPLC: 99\% purity, RT $7.80 \mathrm{~min}$ (method B).

\section{$S, S$-Dimethyldithiocarbonate (51)}<smiles>CSC(=O)SC</smiles>

was purchased from Sigma-Aldrich (Cat. No. 660191).

\section{Methyl $N$-cyanocarbamodithioate potassium salt}

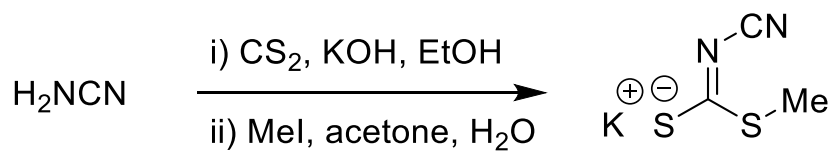

A solution of $\mathrm{KOH}(2.874 \mathrm{~g}, 51.22 \mathrm{mmol})$ in $\mathrm{EtOH}(9 \mathrm{~mL})$ was added to a solution of cyanamide (1.065 g, $25.33 \mathrm{mmol})$ in carbon disulfide $(1.64 \mathrm{~mL}, 27.3 \mathrm{mmol})$ at $0{ }^{\circ} \mathrm{C}$. After stirring overnight at room temperature, the resulting precipitate was filtered, washed with $\mathrm{EtOH}$, dried to provide $N$-cyanocarbamodithioate potassium salt $(1.173 \mathrm{~g}, 7.507$ $\mathrm{mmol})$ as yellow-green solid. Iodomethane $(465 \mu \mathrm{L}, 7.47 \mathrm{mmol})$ was added to a solution of $N$-cyanocarbamodithioate potassium salt $(1.173 \mathrm{~g}, 7.507 \mathrm{mmol})$ in acetone $(5 \mathrm{~mL})$ and 
$\mathrm{H}_{2} \mathrm{O}(5 \mathrm{~mL})$ at $0{ }^{\circ} \mathrm{C}$. The mixture was stirred $20 \mathrm{~h}$ at room temperature under $\mathrm{Ar}$ atmosphere and evaporated. After the residue was suspended in acetone and filtered, the filtrate was evaporated to provide the title compound $(723 \mathrm{mg}, 4.25 \mathrm{mmol})$ as colorless solid in 17\% yield. ${ }^{1} \mathrm{H}-\mathrm{NMR}$ (DMSO- $\left.d 6\right) \delta: 3.33(3 \mathrm{H}, \mathrm{s})$.

\section{$S$-Benzyl- $N$-cyano- $S$ 'methylcarbonimidodithioate (6a)}<smiles>CN=C(SCc1cccc(CBr)c1)SOC</smiles>

Benzyl bromide (95 $\mathrm{\mu L}, 0.80 \mathrm{mmol}$ ) was added to a solution of methyl $\mathrm{N}^{-}$ cyanocarbamodithioate potassium salt $(91 \mathrm{mg}, 0.53 \mathrm{mmol})$ in EtOH $(2 \mathrm{~mL})$. After the mixture was stirred overnight, precipitate was removed, and the filtrate was evaporated. The resulting residue was purified by column chromatography on silica gel (hexane/EtOAc $=5 / 1)$ to provide the title compound $(51 \mathrm{mg}, 0.23 \mathrm{mmol}$ ) as colorless oil in $43 \%$ yield. ${ }^{1} \mathrm{H} \mathrm{NMR}\left(\mathrm{CDCl}_{3}\right)$ 8: 7.38-7.31 $(5 \mathrm{H}, \mathrm{m}), 4.41(2 \mathrm{H}, \mathrm{s}), 2.63(3 \mathrm{H}, \mathrm{s})$. Purity by HPLC: 99.5\%. MS (EI) calcd for $\mathrm{C}_{10} \mathrm{H}_{10} \mathrm{~N}_{2} \mathrm{~S}_{2}$ [M]+: $\mathrm{m} / \mathrm{z} 222.03$, found 222.14 . HPLC: 99\% purity, RT $5.85 \min (\operatorname{method} \mathrm{A})$.

\section{$N$-Cyano- $S$-(2,4-dichlorobenzyl)- $S$ 'methylcarbonimidodithioate (6b)}<smiles>CN=C(SCc1ccc(Cl)cc1Cl)SC(=NC)[As]OC</smiles>

2,4-Dichlorobenzyl chloride $(130 \mu \mathrm{L}, 0.936 \mathrm{mmol})$ was added to a solution of methyl $N^{\text {- }}$ cyanocarbamodithioate potassium salt $(106 \mathrm{mg}, 0.622 \mathrm{mmol})$ in $\mathrm{EtOH}(2 \mathrm{~mL})$. After the mixture was stirred overnight, precipitate was removed, and the filtrate was evaporated. The resulting residue was purified by column chromatography on silica gel (hexane/EtOAc $=5 / 1)$ to provide the title compound (100 $\mathrm{mg}, 0.343 \mathrm{mmol}$ ) as yellow solid in 55\% yield. ${ }^{1} \mathrm{H} \mathrm{NMR}\left(\mathrm{CDCl}_{3}\right) \delta: 7.43(1 \mathrm{H}, \mathrm{d}, J=2.3 \mathrm{~Hz}), 7.41(1 \mathrm{H}, \mathrm{d}, J=7.9 \mathrm{~Hz}), 7.25$ $(1 \mathrm{H}, \mathrm{dd}, J=8.3 \mathrm{~Hz}, 2.3 \mathrm{~Hz}), 4.46$ (2H, s), 2.66 (3H, s). Purity by HPLC: 99.1\%. MS (EI) calcd for $\mathrm{C}_{10} \mathrm{H}_{8} \mathrm{Cl}_{2} \mathrm{~N}_{2} \mathrm{~S}_{2}[\mathrm{M}]+: \quad \mathrm{m} / z \quad 293.94 \quad\left[{ }^{37} \mathrm{Cl}^{37} \mathrm{ClM}\right]^{+}, 291.95 \quad\left[{ }^{37} \mathrm{Cl}{ }^{35} \mathrm{ClM}\right]+, 289.95$ $\left[{ }^{35} \mathrm{Cl}^{35} \mathrm{ClM}\right]^{+}$, found $293.95\left[{ }^{37} \mathrm{Cl}^{37} \mathrm{ClM}\right]^{+}, 291.95\left[{ }^{37} \mathrm{Cl}^{35} \mathrm{ClM}\right]^{+}, 289.96\left[{ }^{35} \mathrm{Cl}^{35} \mathrm{ClM}\right]^{+}$. HPLC: 98\% purity, RT $6.04 \min (\operatorname{method} \mathrm{A})$. 


\section{Biological evaluations rhIDO inhibition}

rhIDO activity was determined as follow. In brief, the standard reaction mixture (200 $\mu \mathrm{L}$ ) contained $50 \mathrm{mM} \mathrm{KPB} \mathrm{(pH} \mathrm{6.5),} 20 \mathrm{mM}$ ascorbic acid (neutralized with $\mathrm{NaOH}$ and $\mathrm{HCl}$ ), $100 \mu \mathrm{g} / \mathrm{mL}$ catalase, $10 \mu \mathrm{M}$ methylene blue, $200 \mathrm{mM}$ L-tryptophan, $5 \mathrm{nM} \mathrm{rhIDO}$, and DMSO solution of the compound $(4 \mu \mathrm{L})$. The reaction was carried out at $37^{\circ} \mathrm{C}$ for 60 min and stopped by the addition of $40 \mu \mathrm{L}$ of $30 \%(\mathrm{w} / \mathrm{v}) \mathrm{CCl}_{3} \mathrm{COOH}$. After heating at $50^{\circ} \mathrm{C}$ for $15 \mathrm{~min}$, the reaction mixture was centrifuged at $15000 \mathrm{~g}$ for $5 \mathrm{~min}$. The supernatant $(150 \mu \mathrm{L})$ was transferred into a well of a 96 -well microplate and mixed with $150 \mu \mathrm{L}$ of $2 \%(\mathrm{w} / \mathrm{v}) 4$-dimethylaminobenzaldehyde in acetic acid. The yellow pigment derived from kynurenine was measured at $490 \mathrm{~nm}$ using SYNERGY H1 microplate reader (BioTek JAPAN).

\section{Kynurenine production in A431 cells}

A431 cells $\left(2.0 \times 10^{5}\right.$ cells $\left./ \mathrm{mL}\right)$ were seeded in a 96-well culture plate $(100 \mu \mathrm{L} /$ well $)$ and grown overnight. Serial DMSO dilutions of compounds $(10 \mu \mathrm{L})$ in a total volume of 200 $\mu \mathrm{L}$ culture medium including tryptophan and human IFN-Y $(5 \mathrm{ng} / \mathrm{mL}$ final concentration) per well were added into wells containing the cells. After an additional 24 $\mathrm{h}$ of incubation, $200 \mathrm{\mu L} /$ well of a mixed solution of $7 \%(\mathrm{v} / \mathrm{v})$ aqueous $\mathrm{CCl}_{3} \mathrm{COOH}$ and $2 \%$ $(\mathrm{w} / \mathrm{v})$ 4-dimethylaminobenzaldehyde in acetic acid (2:5) was added into each well. The yellow colour derived from kynurenine was measured at $460 \mathrm{~nm}$ using a SYNERGY H1 microplate reader (BioTek JAPAN).

\section{Spectroscopic measurements Peptide mapping study}

The mixtures of the rhIDO1 (final concentration $2 \mu \mathrm{g} / 10 \mu \mathrm{L}$ ) with/without compound 4 a (final concentration $75 \mu \mathrm{M}$ ) in reaction conditions were incubated at $37^{\circ} \mathrm{C}$ for $60 \mathrm{~min}$. Final DMSO concentration of mixtures were $1.0 \%$. The samples were treated with $10 \%$ $(\mathrm{v} / \mathrm{v})$ trifluoroacetic acid at $-30^{\circ} \mathrm{C}$ for $30 \mathrm{~min}$ and sedimented at $13,700 \times \mathrm{g}$ for $5 \mathrm{~min}$. The supernatants were discarded and suspended in $100 \mathrm{mM}$ Tris- $\mathrm{HCl}$ (pH 8.0) and sedimented at $13,700 \times \mathrm{g}$ for $5 \mathrm{~min}$. This washing step was repeated three times. The supernatants were discarded and the resulting pellet was suspended in buffer containing $5 \mathrm{mM}$ tris (2-carboxyethyl) phosphine hydrochloride (TCEP) solution $(10 \mu \mathrm{L})$. The samples were incubated in darkness at room temperature for $1 \mathrm{~h}$. After addition of 200 $\mathrm{mM}$ iodoacetamide $(10 \mu \mathrm{L})$, the mixtures were incubated in darkness at room 
temperature for $1 \mathrm{~h}$. The reaction was stopped by the addition of $20 \%$ trifluoroacetic acid solution $(20 \mu \mathrm{L})$. The mixtures were incubated at $-30^{\circ} \mathrm{C}$ for $30 \mathrm{~min}$, sedimented at $13,700 \times \mathrm{g}$ for $5 \mathrm{~min}$, washed with $100 \mathrm{mM}$ Tris $-\mathrm{HCl}(\mathrm{pH}$ 8.0) $\mathrm{x} 3$ and air-dried. The pellets in $50 \mathrm{mM}$ ammonium bicarbonate solution $(20 \mu \mathrm{L})$ were digested with 20:1 protein-trypsin for $24 \mathrm{~h}$ at $37^{\circ} \mathrm{C}$. When the digestion was complete, solvent was removed by Speed Vac. Digested samples were dissolved in FAPH buffer $(10 \mu \mathrm{L})$ and analyzed by UltrafleXtreme (Bruker Daltonics). The target plate and the matrix were Ground Steel and $\alpha$-cyano-4-hydroxycinnamic acid, respectively.

\section{UV-visible absorption spectroscopy study}

The optical absorption spectra were recorded at room temperature using an Amersham Ultrospec 3000 pro spectrophotometer. All the measurements were performed in $50 \mathrm{mM} \mathrm{KBP}$ buffer ( $\mathrm{pH}$ 6.5) with compound concentration of $75 \mu \mathrm{M}$. Namely, $30 \mu \mathrm{L}$ of tested compound ( $300 \mu \mathrm{M}$ in DMSO) was added to a solution of $10 \mu \mathrm{M}$ methylene blue $(6 \mu \mathrm{L}), 200 \mathrm{mM}$ ascorbic acid $(30 \mu \mathrm{M})$ and $50 \mathrm{nM}$ rhIDO1 $(6 \mu \mathrm{M})$ in $50 \mathrm{mM} \mathrm{KPB}(\mathrm{pH}$ 6.5) $(48 \mu \mathrm{L})$ in cuvette. After incubation for $30 \mathrm{~min}$, optical absorption spectra was measured in the range of 350 to $650 \mathrm{~nm}$.

\section{Docking study}

Molecular docking was carried out with the FRED docking program 3.4.0.2 (OpenEye, Inc., Santa Fe, NM) using the highest accuracy while all other parameters were kept at their default value. The crystal structure of IDO1 with inhibitor (PDB 6R63) was used as a receptor. Receptor grid file was prepared using Make Receptor 3.4.0.2 (OpenEye, Inc.) followed by GUI interface. 3D conformer file of compound was generated using Omega 3.1.2.2 (OpenEye, Inc.). 